\title{
Incidence analysis of human leptospirosis in Brazil
}

\author{
Marcelle Moura Silveira ${ }^{\mathrm{a}}$, Fernando Pires Hartwig ${ }^{\mathrm{b}}$, Alan John Alexander McBride ${ }^{\mathrm{a}, c^{*}}$

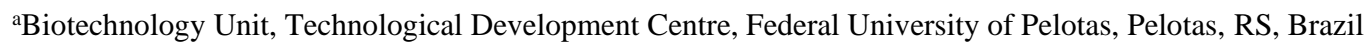 \\ bPostgraduate Programme in Epidemiology, Federal University of Pelotas, Pelotas, RS, Brazil

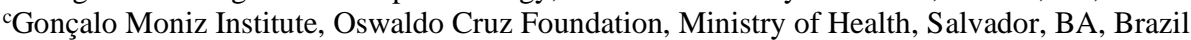

Histórico do Artigo

Recebido em:

10/11/2019

Aceito em:

$29 / 02 / 2020$

Keywords:

Surveillance; incidence; infectious disease

Palavras-chave:

Vigilância; incidência; infecciosa

\begin{abstract}
Leptospirosis is a neglected infectious disease that affects humans and animals with a higher incidence in the tropics and subtropics. In that context, the aim of this study was to describe the temporal distribution of the epidemiology and sociodemographic factors of human leptospirosis in Brazil. The analysis conducted in this study was based to age, gender, area, schooling, region and skin colour reported by Ministry of Health from National Disease Notification System (SINAN) and National Survey of Household Samples (PNAD) database of Brazil, during the period 2007 to 2014. A total of 22,889 cases were reported, the majority of which were registered in male and urban area, more than $70 \%$ and $80 \%$, respectively. The greatest number of cases occur in patients with age group between 20-39 years. However, there was a significant increase in children between 0 and $9\left(\mathrm{p}=2.8 \times 10^{-7}\right), 10$ e $14(\mathrm{p}=0.015)$ e 70 e $79(\mathrm{p}=0.021)$ years old. The North region highlighted in relation to the other regions of the country, with a significant increase $\left(\mathrm{p}=2.4 \times 10^{-}\right.$ ${ }^{11}$ ) in the number of cases. An epidemiological surveillance of leptospirosis is important in Brazil once the incidence of disease is increasing in children and the elderly. We also show are essential efforts between medical and governmental institutions to improve the quality of data. Understand the disease trends can be providing insights into the prevention and control of leptospirosis in Brazil and others development countries.
\end{abstract}

Análise da incidência de leptospirose humana no Brasil

RESUMO

Leptospirose é uma doença infecciosa negligenciada, que afeta humanos e animais com maior incidência nos países tropicais e subtropicais. Nesse contexto, o objetivo deste estudo foi descrever a tendência de análise temporal e fatores sociodemográficos da leptospirose em humana no Brasil. A análise realizada neste estudo foi baseada na idade, sexo, área, escolaridade, região e cor da pele. Os dados obtidos do Sistema Nacional de Notificação de Doenças (SINAN) organizado pelo Ministério da Saúde e do banco de dados da Pesquisa Nacional de Amostras de Domicílios (PNAD) do Brasil, durante no período de 2007 a 2014. Foram relatados 22.889 casos, sendo a maioria destes doença registrados em homens e em área urbana, mais de $70 \%$ e mais de $80 \%$ dos casos, respectivamente. O maior número de casos ocorreu em pacientes com faixa etária entre 20 e 39 anos. No entanto, houve um aumento significativo em crianças com idade entre 0 e $9\left(\mathrm{p}=2.8 \times 10^{7}\right), 10$ e $14(\mathrm{p}=$ $0.015)$ e 70 e $79(p=0.021)$ anos. A região Norte se destacou em relação as demais regiões do país, com um aumento significativo dos casos $\left(\mathrm{p}=2.4 \times 10^{-11}\right)$. A vigilância epidemiológica da leptospirose no Brasil é importante, uma vez que a incidência da doença está aumentando em crianças e idosos. Também mostramos que são necessários esforços essenciais entre instituições médicas e governamentais para melhorar a qualidade dos dados. A análise de tendência temporal da doença pode fornecer informações sobre a prevenção e controle da leptospirose no Brasil e em outros países em desenvolvimento.

\section{Introduction}

Leptospirosis is a neglected zoonotic disease considered an important public health problem with occurrence worldwide. The estimate of the worldwide impact of leptospirosis predicts over 1 million cases and approximately 60,000 deaths per year (1).

\footnotetext{
* Corresponding author: alan.mcbride@ ufpel.edu.br (McBride A.J.A.)
} 
Leptospirosis is caused by infection with pathogenic spirochetes of the genus Leptospira spp. that include 35 species. These are further classified by serology into more than 300 different serovars of which more 250 are known to infect humans (2). Leptospirosis is strongly associated with environmental factors including heavy rainfall, flooding, population growth, poor sanitation and hygiene and disasters $(3,4)$.

Rats and others rodents are the most important reservoirs of Leptospira spp., even though all mammal species can be infected. The transmission of leptospirosis occurs thought direct or indirect contact with the urine of infected animals with pathogenic species. Pathogenic Leptospira spp. penetrate the body through skin lesions or mucosal membranes and can cause an infection with a wide clinical spectrum that ranges from asymptomatic or mild febrile illness to severe disease and death. Weil's disease, characterized by jaundice, renal failure and severe pulmonary haemorrhage syndrome represent the most severe forms, with mortality rates of $>70 \%$ (5).

The Microscopic Agglutination Test (MAT) is the recognized standard test for diagnosis of leptospirosis, however it requires a large panel of live leptospiral cultures and a high level of technical expertise for interpretation of results (6). The difficulty in diagnosis is increased by the fact that the initial symptoms of leptospirosis are similar to other febrile diseases such as dengue, typhoid fever and malaria. This has contributed to the underdiagnosis of the disease and its neglected status, particularly in developing countries (79). With approximately 200 million inhabitants, Brazil is among the most populous countries in the world, approximately $6 \%$ of the population reside in slums and while poverty levels have significantly reduced, almost 10 million people live on less than US $\$ 2$ a day This population group is the most vulnerable to leptospirosis and other povertyrelated infections. Previous studies have highlighted the influence of gender and age on the distribution of leptospirosis in Brazil $(10,11)$.

In addition, another factor contributing to the increased incidence of disease at country is the climate, in tropical zones the heat and humidity favors the transmission of Leptospira spp. (3). In Brazil, notification of human leptospirosis is mandatory and confirmed cases are reported in the databases, In the current study, we analyzed the incidence of human cases of leptospirosis in Brazil.

\section{Materials and methods}

\subsection{Data sources and collection}

An ecological study was undertaken using data obtained from the Pesquisa Nacional por Amostra de Domicílio (PNAD) and the Sistema de Informação de Agravos de Notificação (SINAN) from 2007 to 2014. The SINAN database from the Ministry of Health is available from the Departamento de Informática do SUS (DATASUS). This database is added to by health professionals and includes standard form sociodemographic and clinical information. PNAD is maintained through a partnership between the Ministry of Health and the Instituto Brasileiro de Geografia e Estatística (IBGE). PNAD was the source of the data on the Brazilian population, while information on cases of leptospirosis in Brazil was obtained from SINAN. Only leptospirosis cases diagnosed in the same year that symptoms occurred were included. This minimized the number of prevalent cases and provided a better estimate of leptospirosis incidence. Thus, the incidence was calculated based on the number of cases, provided by SINAN and population information obtained from PNAD. The PNAD does not contain data for 2010, therefore this year was excluded from the analysis. 
Leptospirosis definition was based on the tenth edition of the International Statistical Classification of Diseases and Related Health Problems (CID 10). Reporting confirmed cases of leptospirosis is mandatory in Brazil. Human cases of leptospirosis are defined by the Brazilian Ministry of Health as presenting clinical symptoms consistent with the disease and must be confirmed by laboratory diagnosis (IgM ELISA or the Microscopic Agglutination Test (MAT)). A positive MAT must meet one of the following criteria: (i) seroconversion: first sample nonreactive and a second sample, collected 14-21 days later, with a titre $\geq 1: 200$; (ii) four-fold increase in the titre between two samples; (iii) titre of $\geq 1: 800$ in a single sample. Leptospirosis could also be confirmed by clinicalepidemiological criteria in this case it is considered selected symptoms with epidemiological history (http://189.28.128.100/dab/docs/publicacoes/cadernos_ab/abcad22.pdf).

The variables collected from PNAD and SINAN included: sex (male or female), skin colour/ethnicity (white, brown, black, Asian ancestry or Native American), schooling (0$3,4-7,8-11$ or $\geq 12$ complete years of formal education, or not applicable), area of residence (urban or rural), residential region (South, Southeast, Central-West, Northeast or North of Brazil), see Fig. 1 for details. Additionally, the case outcome (cure, death from the disease or death from other causes) was collected from SINAN. This data was collected for the following age groups: 0-9, 10-14, 15-29, 20-39, 40-59, 60-69, 70-79 and $\geq 80$ complete years to allow age standardization of the incidence estimates.

\subsection{Data harmonisation}

After data collection, the following variables were harmonised: age, schooling and area of residence. In PNAD, age (in complete years) was originally available as follows: 0-9, 10-14, 15-19, 20-24, 25-29, 30-34, 35-39, 40-44, 45-49, 50-59, 60-69, 70-79 and $\geq 80$. While in SINAN, the categories were: $<1,1-4,5-9,10-14,15-19$ 20-39, 40-59, 60-64, $65-69,70-79$ and $\geq 80$. The categorisation used to harmonise the datasets while minimising merging age groups was: 0-9, 10-14, 15-29, 20-39, 40-59, 60-69, 70-79 and $\geq 80$.

Schooling was available in PNAD as complete years of formal education: 0-3, 4-7, 8$10,11, \geq 12$ or not applicable. In SINAN, this variable was available as: no formal education, complete $1^{\text {st }}$ to incomplete $4^{\text {th }}$ year of primary school, complete $4^{\text {th }}$ year of primary school, complete $5^{\text {th }}$ to incomplete $8^{\text {th }}$ year of primary school, complete primary school, incomplete secondary school, complete secondary school, incomplete higher education, complete higher education or not applicable (NA). To harmonise this variable between datasets the SINAN education categories were converted to their equivalents in complete years of formal education: $0,1-3,4,5-7,8,9-10,11,12-14, \geq 15$ or NA. Then, education in both datasets was re-categorized as: $0-3,4-7,8-11, \geq 12$ or NA. A further harmonisation step was necessary when the number of individuals in the NA category was missing. In this case, this number was estimated by subtracting the sum of the number of individuals in the remaining schooling categories (for a given year and age group) from the total number of individuals in the corresponding year and age group.

In PNAD there were two categories for area of residence: urban and rural. However, the SINAN database contained three categories: urban, peri-urban and rural. For harmonisation, individuals in the peri-urban category were included in the urban category.

\subsection{Statistical analysis}


Proportions of each category of sex, age, skin colour, schooling, residential area and country region for each year were determined for the Brazilian population and for incident leptospirosis cases. Leptospirosis incidence was reported per 100,000 individuals. Agestandardised incidence estimates were obtained by applying age-specific estimates to the age structure of the Brazilian population in 2014 (i.e., direct age standardisation).

Mean annual variation in leptospirosis incidence was calculated using unadjusted and age-standardised leptospirosis incidence estimates using the formula below (12):

$\sqrt[7]{\left[1+\left(\mathrm{I}_{2014}-\mathrm{I}_{2007}\right)\right] / \mathrm{I}_{2007}}$, where $\mathrm{I}_{2007}$ and $\mathrm{I}_{2014}$ correspond to leptospirosis incidence in 2007 and 2014, respectively. p-values were based on a likelihood-ratio chi-squared test with 1 degree of freedom from a generalised linear model (dependent variable: incidence; independent variable: years) with Gaussian family and natural logarithmic link function.

Proportions of missing data in incident leptospirosis cases in each year were present for skin colour, schooling and disease outcome, as well as proportions of each disease outcome. Mean annual variation in such proportions and associated p-values were obtained as described above. All analyses were performed in R version 3.2.4 (www.rproject.org).

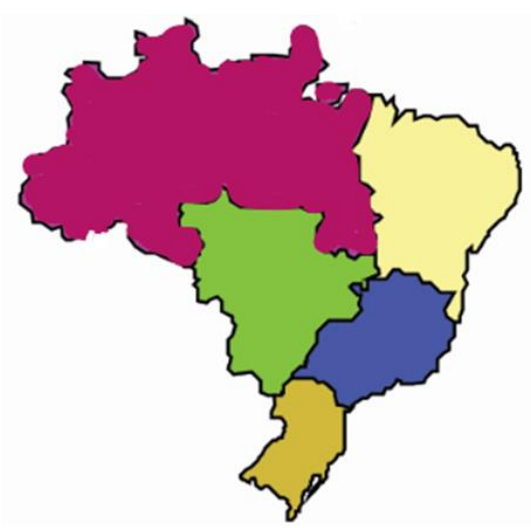

Figure 1 - Geographical location of the study area. North - purple; North-east -yellow; Central - green; South-east - blue; South - brown

\section{Results}

\subsection{Distribution of cases, incidence and mortality}

Sociodemographic characteristics of the Brazilian population from 2007 to 2014. During the study period, 30,216 confirmed cases were registered in Brazil, see Fig. 1. In general, the country region with the highest number of registered cases of leptospirosis was the Southeast, followed by South, Northeast, North and Central-West, Table 1. There was an average increase of $1.3 \%$ per year in the incidence of registered cases in the North region of Brazil $\left(\mathrm{p}=2.4 \times 10^{-11}\right)$, Table 2 . The number of cases/year ranged from 3,120 to 4,845 and incidence varied from 1.6 to 2.4 per 100,000 individuals, Table 1 and Fig. 2. The number of cases peaked in 2011 with 4,843 cases (an incidence of 2.4 per 100,000 individuals) and then again in 2014 with 4,619 cases (incidence of 2.3 per 100,000 individuals). Although the number of cases increased in recent years, the proportion of deaths from leptospirosis changed $0.94 \%$ per year on average $(\mathrm{p}=0.001)$.

\subsection{Infection according to sex and age groups}


From 2007 to 2014, more than $70 \%$ of the registered cases were males, Table 1 . The incidence of registered cases increased $1.06 \%$ per year in females $(p=0.004)$ on average. Such trend was not observed in males $(\mathrm{p}=0.547)$, Table 2 . Analyses within age groups showed that the most cases were individuals with 20-39 years (about 40\%) and 40-59 years of age (about $30 \%$ ). The least common age was the 80 or older group. Of note, the mean variation in incidence of leptospirosis was $1.12 \%, 1.11 \%$ and $1.03 \%$ per year during the study period in age groups $0-9$ years $(\mathrm{p}=2.8 \times 10-7), 10-14$ years $(\mathrm{p}=0.015)$ and 70 79 years $(\mathrm{p}=0.021)$, respectively. All other age groups presented directionally-consistent estimates of mean variation in incidence but failed to achieve conventional levels of statistical significance.

\subsection{Additional Demographical Data}

More than eight out of ten of registered cases of leptospirosis in Brazil occurred in urban areas (Table 1). None of the analysis of incidence time trends within residential areas achieved conventional levels of statistical significance (Table 2). Regarding skin colour, the proportion of cases that self-classified as white decreased from 61.7\% in 2007 to $41.3 \%$ in 2014. An opposite trend was observed for brown individuals, with an increase from $30.2 \%$ to $52.9 \%$ in the same period, Table 1 . The incidence increased in $1.12 \%$ per year on average among brown individuals $(\mathrm{p}=0.003)$. No important trends were observed in the other skin colour groups, Table 2.

Regarding schooling (Table 1), more than $70 \%$ of registered cases occurred in individuals with 4-7 years of education $(32.1 \%$ to $44.2 \%)$ and with $8-11$ years of education (34.4\% to $39.6 \%)$. There was an average increase in incidence of $1.11 \%$ per year in individuals with $0-3$ years of age $(\mathrm{p}=0.048)$, but the test failed to achieve conventional levels of statistical significance in the crude (i.e., age-unadjusted) estimate $(\mathrm{p}=0.120)$. Such failure also occurred in all other schooling groups, but all presented directionally-consistent estimates.

\subsection{Missing data}

We also analysed missing data patterns regarding skin colour, schooling and disease outcome in the leptospirosis cases registered in SINAN (Table 3). These proportions ranged from $11.9 \%$ to $14.2 \%$ for skin colour, $29.7 \%$ to $37.7 \%$ for schooling and $6.4 \%$ to $8.1 \%$ for disease outcome. In all cases, none of the analyses achieved conventional levels of statistical significance (mean annual variations of 0.98 and $1.00 ; p>0.250$ ). 


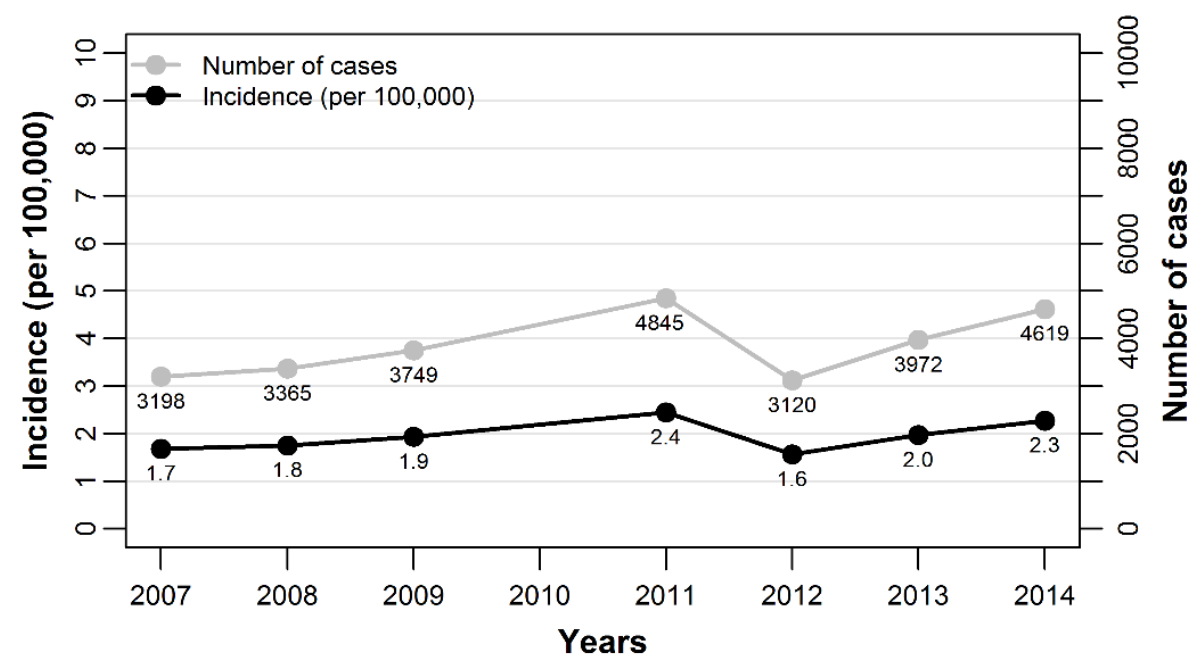

Figure 2 - Number of incidence leptospirosis cases and leptospirosis incidence (per 100,000 individuals) in Brazil from 2007 to 2014.

Table 1 - Description of leptospirosis cases in Brazil from 2007 to 2014. According to sociodemographic characteristics (information obtained from SINAN). Values are percentages $^{\mathrm{a}}$.

\begin{tabular}{|c|c|c|c|c|c|c|c|}
\hline Variable & 2007 & 2008 & 2009 & 2011 & 2012 & 2013 & 2014 \\
\hline \multicolumn{8}{|l|}{ Sex } \\
\hline Males & 78.6 & 80.4 & 83.6 & 79.6 & 76.2 & 76.4 & 74.8 \\
\hline Females & 21.4 & 19.6 & 16.4 & 20.4 & 23.8 & 23.6 & 25.2 \\
\hline \multicolumn{8}{|l|}{ Age } \\
\hline $0-9$ & 3.3 & 3.8 & 3.4 & 3.0 & 4.5 & 4.0 & 4.5 \\
\hline $10-14$ & 5.7 & 7.0 & 6.0 & 6.0 & 6.6 & 5.9 & 7.4 \\
\hline $15-19$ & 11.0 & 10.5 & 10.3 & 9.7 & 8.6 & 10.0 & 9.8 \\
\hline $20-39$ & 42.5 & 42.6 & 44.1 & 40.7 & 40.6 & 40.8 & 40.7 \\
\hline $40-59$ & 30.6 & 29.8 & 29.2 & 32.6 & 30.7 & 30.7 & 29.2 \\
\hline $60-69$ & 4.8 & 4.6 & 5.0 & 5.8 & 6.6 & 5.7 & 5.7 \\
\hline $70-79$ & 1.8 & 1.4 & 1.7 & 1.8 & 2.2 & 2.4 & 2.2 \\
\hline$\geq 80$ & 0.3 & 0.3 & 0.3 & 0.4 & 0.3 & 0.5 & 0.4 \\
\hline \multicolumn{8}{|l|}{ Skin colour } \\
\hline White & 61.7 & 60.1 & 53.5 & 55.6 & 51.6 & 47.8 & 41.3 \\
\hline Brown & 30.2 & 32.0 & 39.4 & 37.6 & 40.9 & 44.4 & 52.9 \\
\hline Black & 6.4 & 7.2 & 6.4 & 6.0 & 6.6 & 6.8 & 4.7 \\
\hline Asian ancestry & 1.1 & 0.6 & 0.6 & 0.4 & 0.6 & 0.7 & 0.7 \\
\hline Native American & 0.5 & 0.1 & 0.2 & 0.4 & 0.3 & 0.3 & 0.4 \\
\hline \multicolumn{8}{|l|}{ Schooling } \\
\hline $0-3$ & 16.4 & 19.1 & 20.3 & 19.3 & 16.2 & 19.0 & 18.9 \\
\hline $4-7$ & 44.2 & 39.1 & 38.5 & 35.3 & 35.4 & 33.5 & 32.1 \\
\hline $8-11$ & 34.4 & 35.7 & 34.8 & 37.5 & 39.2 & 39.5 & 39.6 \\
\hline$\geq 12$ & 3.0 & 3.8 & 3.6 & 5.3 & 5.4 & 4.7 & 5.3 \\
\hline N/A & 2.1 & 2.3 & 2.9 & 2.5 & 3.8 & 3.4 & 4.1 \\
\hline \multicolumn{8}{|l|}{ Area } \\
\hline Urban & 83.6 & 86.5 & 80.4 & 84.7 & 84.5 & 83.2 & 85.8 \\
\hline Rural & 16.4 & 13.5 & 19.6 & 15.3 & 15.5 & 16.8 & 14.2 \\
\hline \multicolumn{8}{|l|}{ Region } \\
\hline South & 38.0 & 44.5 & 27.6 & 34.6 & 28.5 & 27.0 & 22.8 \\
\hline Southeast & 37.0 & 28.0 & 38.0 & 36.2 & 40.5 & 35.5 & 27.4 \\
\hline Central-West & 1.0 & 1.4 & 1.1 & 0.5 & 1.6 & 1.6 & 1.3 \\
\hline Northeast & 16.7 & 17.2 & 24.1 & 18.8 & 12.9 & 12.9 & 12.1 \\
\hline North & 7.3 & 8.9 & 9.0 & 9.9 & 16.4 & 22.9 & 36.5 \\
\hline $\begin{array}{l}\text { Total number of } \\
\text { cases }\end{array}$ & 3,198 & 3,365 & 3,749 & 4,845 & 3,120 & 3,972 & 4,619 \\
\hline
\end{tabular}

Individuals with missing data for a given variable were excluded from both the numerator and the denominator. 
Table 2 - Unadjusted and age-standardised mean annual variation in leptospirosis incidence in Brazil from 2007 to 2014 within groups of sociodemographic variables.

\begin{tabular}{|c|c|c|c|c|}
\hline \multirow[t]{2}{*}{ Variable } & \multicolumn{2}{|c|}{ Unadjusted } & \multicolumn{2}{|c|}{ Age-standardised } \\
\hline & $\begin{array}{l}\text { Mean annual } \\
\text { variation }(\%)\end{array}$ & p-value ${ }^{a}$ & $\begin{array}{l}\text { Mean annual } \\
\text { variation }(\%)\end{array}$ & p-value ${ }^{a}$ \\
\hline \multicolumn{5}{|l|}{ Sex } \\
\hline Males & 1.04 & 0.496 & 1.03 & 0.547 \\
\hline Females & 1.07 & 0.004 & 1.06 & 0.005 \\
\hline \multicolumn{5}{|l|}{ Age } \\
\hline $0-9$ & 1.12 & $2.8 \times 10^{-7}$ & - & - \\
\hline $10-14$ & 1.11 & 0.015 & - & - \\
\hline $15-19$ & 1.03 & 0.524 & - & - \\
\hline $20-39$ & 1.04 & 0.325 & - & - \\
\hline $40-59$ & 1.02 & 0.584 & - & - \\
\hline $60-69$ & 1.03 & 0.310 & - & - \\
\hline $70-79$ & 1.03 & 0.021 & - & - \\
\hline$\geq 80$ & 1.01 & 0.695 & - & - \\
\hline \multicolumn{5}{|l|}{ Skin colour ${ }^{b}$} \\
\hline White & 1.00 & 0.785 & 1.00 & 0.783 \\
\hline Brown & 1.13 & 0.002 & 1.12 & 0.003 \\
\hline Black & 0.98 & 0.299 & 0.98 & 0.270 \\
\hline Asian ancestry & 1.00 & 0.660 & 1.01 & 0.486 \\
\hline Native American & 0.98 & 0.664 & 1.00 & 0.431 \\
\hline \multicolumn{5}{|l|}{ Schooling } \\
\hline $0-3$ & 1.10 & 0.120 & 1.11 & 0.048 \\
\hline $4-7$ & 1.02 & 0.979 & 1.02 & 0.724 \\
\hline $8-11$ & 1.05 & 0.268 & 1.05 & 0.248 \\
\hline$\geq 12$ & 1.07 & 0.314 & 1.07 & 0.288 \\
\hline N/A & 1.17 & $1.4 \times 10^{-8}$ & 1.17 & $3.8 \times 10^{-9}$ \\
\hline \multicolumn{5}{|l|}{ Area } \\
\hline Urban & 1.04 & 0.285 & 1.04 & 0.306 \\
\hline Rural & 1.04 & 0.263 & 1.04 & 0.322 \\
\hline \multicolumn{5}{|l|}{ Region } \\
\hline South & 0.97 & 0.283 & 0.97 & 0.278 \\
\hline Southeast & 1.00 & 0.563 & 1.00 & 0.580 \\
\hline Central-West & 1.08 & 0.181 & 1.08 & 0.197 \\
\hline Northeast & 1.00 & 0.545 & 0.99 & 0.522 \\
\hline North & 1.31 & $7.7 \times 10^{-12}$ & 1.30 & $2.4 \times 10^{-11}$ \\
\hline Brazil & 1.04 & 0.227 & 1.04 & 0.285 \\
\hline
\end{tabular}

${ }^{a} P$-values based on a likelihood-ratio chi-squared test with 1 degree of freedom from a generalised linear model (dependent variable: incidence; independent variable: years) with Gaussian family and natural logarithmic link function.

${ }^{b}$ For age standardisation of leptospirosis incidence within skin colour categories, the oldest age group ( $\geq 80$ years) was excluded due to missing information in this age group regarding the number of Native American individuals.

Table 3 - Case-case comparisons: proportion of missing information for incident leptospirosis cases regarding skin colour, schooling and disease outcome, and proportions of each disease outcome.

\begin{tabular}{|c|c|c|c|c|c|c|c|c|c|}
\hline \multirow[t]{2}{*}{ Variable } & \multicolumn{7}{|c|}{ Year } & \multirow{2}{*}{$\begin{array}{l}\text { Mean annual } \\
\text { variation }(\%)\end{array}$} & \multirow[t]{2}{*}{ p-value ${ }^{\mathrm{a}}$} \\
\hline & 2007 & 2008 & 2009 & 2011 & 2012 & 2013 & 2014 & & \\
\hline \multicolumn{10}{|l|}{ Missing data (\%) } \\
\hline Skin colour & 14.2 & 9.6 & 14.3 & 12.7 & 11.7 & 12.0 & 11.9 & 0.98 & 0.624 \\
\hline Schooling & 34.6 & 29.7 & 37.1 & 36.9 & 37.0 & 37.7 & 34.0 & 1.00 & 0.311 \\
\hline Disease outcome & 8.1 & 7.3 & 7.9 & 7.2 & 6.4 & 8.0 & 6.9 & 0.98 & 0.265 \\
\hline \multicolumn{10}{|l|}{ Disease outcome $(\%)^{b}$} \\
\hline Cure & 87.4 & 89.5 & 89.8 & 89.6 & 89.6 & 89.2 & 91.9 & 1.01 & 0.022 \\
\hline Death from leptospirosis & 11.6 & 9.8 & 9.6 & 9.6 & 9.0 & 9.5 & 7.5 & 0.94 & 0.001 \\
\hline Death from other causes & 1.0 & 0.8 & 0.6 & 0.8 & 1.4 & 1.3 & 0.6 & 0.94 & 0.563 \\
\hline
\end{tabular}

${ }^{a} P$-values based on a likelihood-ratio chi-squared test with 1 degree of freedom from a generalised linear model (dependent variable: proportions; independent variable: years) with Gaussian family and natural logarithmic link function.

bIndividuals with missing data for disease outcome were excluded from the denominator. 

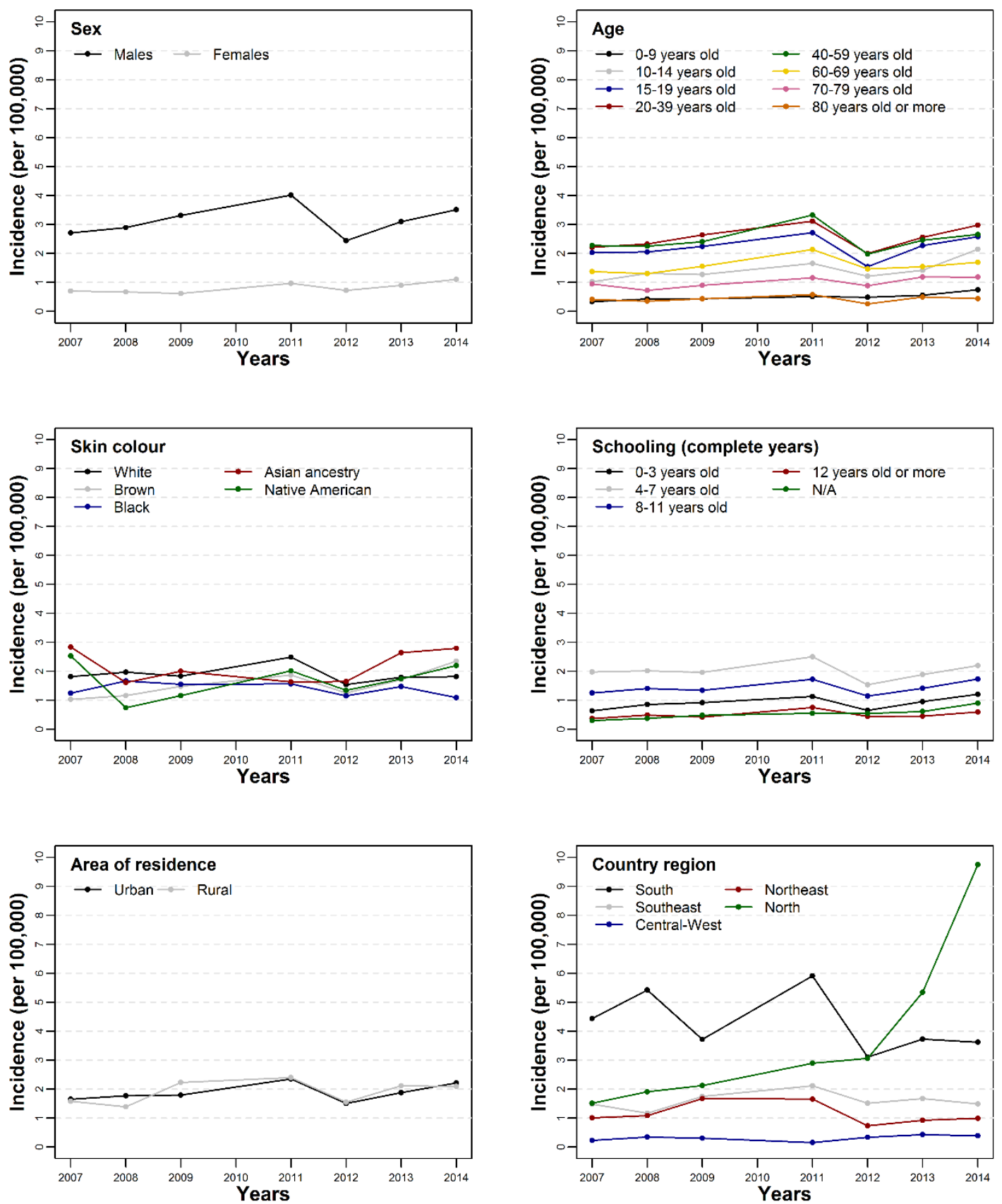

Figure 2 - Unadjusted leptospirosis incidence (per 100,000 individuals) in Brazil from 2007 to 2014 within subgroups of sociodemographic variables.

\section{Discussion}

Leptospirosis is a serious public health problem in Brazil and other developing countries. The main objective of this study was to determine the incidence of human leptospirosis in Brazil from 2007 to 2014. With an average of 3,837 cases reported annually, the true incidence is likely much higher as leptospirosis is commonly misdiagnosed due unreliable laboratory diagnostic testing (13). During the study period we found that most of confirmed cases were reported in males aged between 20-39 years old and that they were concentrated in urban areas (Table 1). In addition, our analysis 
found significant increases in incidence among females, children, the elderly and especially in the North of Brazil (Table 2).

The higher number of cases of leptospirosis among males is probably due to the tendency for males to be involved in high-risk activities including: cleaning open sewers, handling infected animals, scavenging in high-risk areas (e.g. rubbish dumps) and exposure to contaminated flood water (1). A higher incidence in males of leptospirosis was also reported in Italy (14), Denmark (15) Korea (16), Fiji (17), Netherlands (18) and Japan (19). Furthermore, these results accord with studies performed in Brazil $(11,20)$. It has also been described that a significant predominance of males with severe infections and a high prevalence of pulmonary manifestations (21). Although most cases $(23,786)$ of leptospirosis were in males, we observed a significant increase in incidence among females, however, the contributing factors remain to be determined.

Since the original observation of how leptospirosis changed from a rural to an urban public health problem, most of the confirmed cases $(24,065)$ occurred in urban zones as previously reported in other Latin-American countries (22-24). The rapid urbanization and the creation of urban slums, which are characterized by a high population density and where there is the lack of basic sanitation contribute to rodent-borne transmission (13). The risk for leptospiral infection in urban slums has also been associated environmental factors as heavy rainfall events. This factor mainly affects slum inhabitants due to floodrisk areas and areas infested by rodents (5). Furthermore, has been suggested that there exist large numbers of inhabitants among slum residents who are repeatedly infected with leptospirosis (25). However, it is important to consider that in the rural zone probably more cases are underreporting due to the difficulty to access reference laboratory.

Our study is in accordance with the literature showing that the most cases of leptospirosis occurred in individuals aged from 20-39 years old, followed by those aged 40-59 years old $(18,26)$. Adults in these age groups are at increased risk due to occupational exposure such as miners, farmers, and abattoir and sewer workers (27). We also identified that from 2011-2014, individuals aged between 0-9, 10-14 and 70-79 years old were significantly more likely to develop leptospirosis. The highest incidence in the 0-14 years old could be considered, for being unusually for leptospirosis. However, age has been described as a risk factor for leptospirosis and likely relates to age-specific behaviors (17). The increased incidence in children living in slums is probably due the them spending more time playing in contaminated environments or with infected pets (17).

There was an increased incidence in the North region of the country between the years 2012 and 2014. Leptospirosis is known to be seasonal, and associated with rainfall in other countries $(22,26)$ and Brazil $(3,28)$. According to Research Company of Mineral Resources (CPRM), the agency responsible for monitoring rainfall, in 2012 there was an exceptional level of flooding recorded in the state of Acre, in the North of Brazil. This phenomenon, which was responsible for the largest flood on record for the last 15 years could be at least partly attributed to an increased incidence in the North region in 2012. Moreover, in 2011, some of the Central Laboratories for Public Health (LACEN) started to use an ELISA-IgM as screening for the diagnosis of leptospirosis, positive or indeterminate results were confirmed by the MAT. Although improvement in diagnostic in the north is a plausible hypothesis to explain the increasing incidence in this region, given the total lack of data on literature about other factors that can also contribute to it, is particularly difficult to determine why this happened.

This is the first report of an analysis of the trend patterns of human leptospirosis in Brazil. A total of 30,216 cases of leptospirosis were reported in Brazil and the incidence range of 1.6 to 2.4 per 100,000 individuals between the years 2007 and 2014. These 
incidences are higher than those reported by other countries in studies performed in the same years as Korea that incidence range of 0.10 to 0.42 per 100,000 individuals during the years 2007 and 2011 (16) and in Mexico incidence rate range of 1.1 to 0.5 per 100,000 individuals between the years 2007 and 2010 (22).

Our data additionally show that during the study period there was a significant reduction in the number of deaths due to leptospirosis in Brazil. On the other hand, we also evidenced the leptospirosis incidence increased among brown individuals (p-0.003). Inequity in health among non-white skin color was previously described in Brazil (29).

While information from national health databases is an important source of secondary data, missing date can be a major problem. When we analyzed missing data for skin colour, education and disease outcome there was no significant difference between the data available from 2007 and 2014. This suggests that there has been no improvement in the quality of the data obtained for leptospirosis during these seven years. Improving the quality of the data is important towards better understanding the disease and the health indicators in Brazil. A major limitation in any study of leptospirosis is the lack of a quality laboratory diagnosis. The clinical symptoms of leptospirosis infection are similar to those of other febrile illnesses including dengue (1). Combined with poor laboratory diagnosis this means that it is difficult to determine the true incidence of the disease. The significant increase in the incidence of leptospirosis in the North of Brazil maybe explained by increased vigilance and notification of cases during the study period, although this is not reflected in the literature. Another important consideration is that due to the limitations in the information available in the National secondary data sources, an approximation was used to compute the incidence estimates. However, this problem was likely minimized by conservatively limiting cases to those whose disease was confirmed in the same year that the first symptoms were reported. Another limitation was that the PNAD was not conducted in 2010; therefore, this year were not included in the incidence time trend analyses. Although there were significant differences the incidence of registered leptospirosis cases in females during the study period, we did not find information in the literature to explain this observation.

\section{Conclusions}

Our study demonstrates that the most cases of leptospirosis are reported in young adult males. However, there was a significant increase in incidence among females, elderly, the children and in the North region of the country. The observations of the current study should provide useful information to guide public health interventions. Time trend analyses are important because leptospirosis incidence may vary temporally due to local variability e.g. in rainfall and flooding. In addition, socio-demography factors are essential towards understanding the epidemiology of any disease.

6. Conflict of interest: The authors declare that they have no conflict of interest.

\section{References}

1. Costa F, Hagan JE, Calcagno J, Kane M, Torgerson P, Martinez-Silveira MS, et al. Global Morbidity and Mortality of Leptospirosis: A Systematic Review. PLoS neglected tropical diseases 2015; 9(9): e0003898.

2. Thibeaux R, Iraola G, Ferres I, Bierque E, Girault D, Soupe-Gilbert ME, et al. Deciphering the unexplored Leptospira diversity from soils uncovers genomic evolution to virulence. Microbial 
genomics 2018; 4(1): 18:46-52.

3. Jorge S, Schuch RA, de Oliveira NR, da Cunha CEP, Gomes CK, Oliveira TL, et al. Human and animal leptospirosis in Southern Brazil: A five-year retrospective study. Travel medicine and infectious disease 2017; 18:46-52.

4. Santos SY, Silva EB, Junior JFO, Santos PJ. Diagnóstico da morbidade e mortalidade dos casos de leptospirose no Nordeste brasileiro entre 2000 a 2015. Enciclopédia Biosfera, Centro Científico Conhecer - Goiânia. 2018; 15(27): 107-118.

5. Hagan JE, Moraga P, Costa F, Capian N, Ribeiro GS, Wunder EA, Jr., et al. Spatiotemporal Determinants of Urban Leptospirosis Transmission: Four-Year Prospective Cohort Study of Slum Residents in Brazil. PLoS Negl Trop Dis 2016; 10(1): e0004275.

6. Haake DA, Levett PN. Leptospirosis in humans. Current topics in microbiology and immunology 2015; 387:65-97.

7. Capeding MR, Chua MN, Hadinegoro SR, Hussain, II, Nallusamy R, Pitisuttithum P, et al. Dengue and other common causes of acute febrile illness in Asia: an active surveillance study in children. PLoS neglected tropical diseases 2013; 7(7): e2331.

8. McBride AJ, Santos BL, Queiroz A, Santos AC, Hartskeerl RA, Reis MG, et al. Evaluation of four whole-cell Leptospira-based serological tests for diagnosis of urban leptospirosis. Clinical and vaccine immunology: CVI 2007; 14(9): 1245-8.

9. Conrad NL, Cruz McBride FW, Souza JD, Silveira MM, Felix S, Mendonca KS, et al. LigB subunit vaccine confers sterile immunity against challenge in the hamster model of leptospirosis. PLoS neglected tropical diseases 2017; 11(3): e0005441.

10. Santos IOC, Landi MFA, Lima EMM, Cruz LM, Bofill MIR, Santos DED, et al. Socio-epidemiological characterization of human leptospirosis in the Federal District, Brazil, 2011-2015. Revista da Sociedade Brasileira de Medicina Tropical 2018; 51(3): 372-5.

11. Oliveira MAA, Leal EA, Correia MA, Serufo Filho JC, Dias RS, Serufo JC. Human leptospirosis: occurrence of serovars of Leptospira spp. in the state of Minas Gerais, Brazil, from 2008 to 2012. Brazilian journal of microbiology : [publication of the Brazilian Society for Microbiology] 2017; 48(3): 483-8.

12. Wehrmeister FC, Menezes AM, Cascaes AM, Martinez-Mesa J, Barros AJ. Time trend of asthma in children and adolescents in Brazil, 1998-2008. Rev Saude Publica 2012; 46(2): 242-50.

13. McBride AJ, Athanazio DA, Reis MG, Ko AI. Leptospirosis. Current opinion in infectious diseases 2005; 18(5): 376-86

14. Ciceroni L, Stepan E, Pinto A, Pizzocaro P, Dettori G, Franzin L, et al. Epidemiological trend of human leptospirosis in Italy between 1994 and 1996. European journal of epidemiology 2000; 16(1): 79-86.

15. van Alphen LB, Ethelberg S, Villumsen S, Krogfelt KA. Trends in human leptospirosis in Denmark, 1980 to 2012. Euro surveillance : bulletin Europeen sur les maladies transmissibles = European communicable disease bulletin 2015; 20(9): 21054

16. Kim MJ. Leptospirosis in the republic of Korea: historical perspectives, current status and future challenges. Infection \& chemotherapy 2013; 45(2): 137-44.

17. Lau CL, Watson CH, Lowry JH, David MC, Craig SB, Wynwood SJ, et al. Human Leptospirosis Infection in Fiji: An Eco-epidemiological Approach to Identifying Risk Factors and Environmental Drivers for Transmission. PLoS neglected tropical diseases 2016; 10(1): e0004405.

18. Goris MG, Boer KR, Duarte TA, Kliffen SJ, Hartskeerl RA. Human leptospirosis trends, the Netherlands, 1925-2008. Emerg Infect Dis 2013; 19(3): 371-8.

19. Lee MJ, Miki S, Kitagawa M, Lee WC. Comparative study on the epidemiology of human leptospirosis in Korea and Japan, 2006-2012. Jpn J Infect Dis 2015; 69(3): 259-61.

20. Silva LA, Lima KM, Fernandes OC, Balassiano IT, Avelar KE, Jesus MS. Seroprevalence of and risk factors for leptospirosis in the City of Manaus, State of Amazonas, Brazil. Revista da Sociedade Brasileira de Medicina Tropical 2016; 49(5): 628-31.

21. Pages F, Polycarpe D, Dehecq JS, Picardeau M, Caillere N, Jaffar-Bandjee MC, et al. Human leptospirosis on Reunion Island: past and current burden. Int J Environ Res Public Health 2014; 11(1): 968-82.

22. Sanchez-Montes S, Espinosa-Martinez DV, Rios-Munoz CA, Berzunza-Cruz M, Becker I. Leptospirosis in Mexico: Epidemiology and Potential Distribution of Human Cases. PloS one 2015; 
10(7): $\mathrm{e} 0133720$.

23. Johnson MA, Smith H, Joeph P, Gilman RH, Bautista CT, Campos KJ, et al. Environmental exposure and leptospirosis, Peru. Emerging infectious diseases. 2004; 10(6): 1016-22.

24. Bello S, Rodriguez M, Paredes A, Mendivelso F, Walteros D, Rodriguez F, et al. [Epidemiological surveillance of human leptospirosis in Colombia, 2007-2011]. Biomedica : revista del Instituto Nacional de Salud 2013; 33 Suppl 1: 153-60.

25. Felzemburgh RD, Ribeiro GS, Costa F, Reis RB, Hagan JE, Melendez AX, et al. Prospective study of leptospirosis transmission in an urban slum community: role of poor environment in repeated exposures to the Leptospira agent. PLoS Negl Trop Dis 2014; 8(5): e2927.

26. Benacer D, Thong KL, Min NC, Verasahib KB, Galloway RL, Hartskeerl RA, et al. Epidemiology of human leptospirosis in Malaysia, 2004-2012. Acta Trop 2016; 157: 162-8.

27. Sarkar U, Nascimento SF, Barbosa R, Martins R, Nuevo H, Kalofonos I, et al. Population-based casecontrol investigation of risk factors for leptospirosis during an urban epidemic. The American journal of tropical medicine and hygiene. 2002; 66(5): 605-10.

28. Ghizzo Filho J, Nazario NO, Freitas PF, Pinto GA, Schlindwein AD. Temporal analysis of the relationship between leptospirosis, rainfall levels and seasonality, Santa Catarina, Brazil, 2005-2015. Revista do Instituto de Medicina Tropical de Sao Paulo 2018; 60:e39.

29. Drummond ED, Simoes TC, Andrade FB. Access to prescribed medicine in the Brazilian adult population. Revista brasileira de epidemiologia = Brazilian journal of epidemiology 2018; 21 :e180007. 